\title{
Rotating-Tungsten Narrow-Groove GTAW for Thick Plates
}

\section{Rotating nonaxisymmetric tungsten ensures sidewall penetration}

\author{
BY C. JIA, Q. YAN, B. WEI, AND C. WU
}

\begin{abstract}
A novel rotating-tungsten narrow-groove gas tungsten arc welding (RT-NG-GTAW) process was proposed based on a specially designed nonaxisymmetric and rotating tungsten electrode. The tungsten electrode was ground with its tip deviated from the axis and located on the column wall. The rotation made the tungsten tip continue circling in the narrow groove. The distance from the tungsten tip to the sidewalls and the bottom weld pool periodically changed. According to the principle of minimum voltage, the arc burning was controlled and maintained periodically from the left sidewall, bottom of the weld pool, and the right sidewall. The rotating arc heated the base metal reliably and evenly on the sidewalls and bottom metal. This technology can solve the key problem of incomplete fusion on sidewalls in narrow-groove welding. A novel welding torch was designed and manufactured. Experiments were conducted, including single-pass narrow-groove welding and narrow-groove butt joint welding experiments using 16-mm-thick alloy steel plates. Results verified that the new technology could improve sidewall fusion and ensure a uniform and smooth weld appearance. The periodically rotating arc kept constantly stirring the molten pool throughout from its formation to solidification. The preliminary investigation showed the novel technology has prospects for thick-plate welding in industry.
\end{abstract}

\section{KEYWORDS}

- Narrow-Groove Gas Tungsten Arc Welding

- Thick-Plate Welding • Rotating Tungsten

- Sidewall Penetration

\section{Introduction}

\section{Narrow-Groove Welding}

With the rapid development of industry, narrow-groove welding has become the first choice for thick-plate welding in fields such as naval architecture, ocean engineering, the petrochemical industry, and heavy machinery. Narrowgroove welding offers the promise of a dramatically improved weld completion rate and significantly reduced heat input (Refs. 1, 2). According to different heat sources, it includes narrow-groove electron beam welding (EBW), narrow-groove laser beam welding (NG-LBW), and narrowgroove arc welding technologies.

Considerable efforts have been devoted to the development of EBW as an alternative fabrication technique for nuclear pressure vessel production (Refs. 3, 4). The double-wall vacuum vessel inner components in advanced fusion reactors like keys, shells, and ribs are usually manufactured using EBW (Ref. 5). However, the high-priced equipment and vacuum environment requirement significantly limit its wide application. For laser beam welding, typical penetration depths are in the range of $1-2 \mathrm{~mm} / \mathrm{kW}$ laser power (Ref. 6). Narrow-groove laser welding can weld materials with thicknesses that are well beyond the capabilities of single-pass autogenous laser welding (Ref. 7). Nilsen et al. (Ref. 8) proposed a dual-vision and spectroscopic sensing approach to trace narrow-groove butt joints during laser welding, which avoided detrimental incomplete sidewall fusion. However, the high-price equipment and high-cost maintenance significantly limit its industrial application.

Generally, the heat input for high EBW is much lower than that for arc welding, as are the expected levels of residual stress and distortion. However, its costs are much higher than that of arc welding. Based on the advantages like low cost, easy accessibility, and easy operation, arc welding has been widely applied in various industrial fields. Narrowgroove arc welding methods mainly include submerged arc welding (SAW), gas metal arc welding (GMAW), and gas tungsten arc welding (GTAW).

\section{NarroW-Groove SAW and GMAW}

Submerged arc welding (SAW) is a high-efficiency welding method featuring high deposition efficiency, slag protection, and the absence of a strong arc (Ref. 9). Manzoli et al. (Ref. 10) employed a new submerged-arc narrow-groove 
A

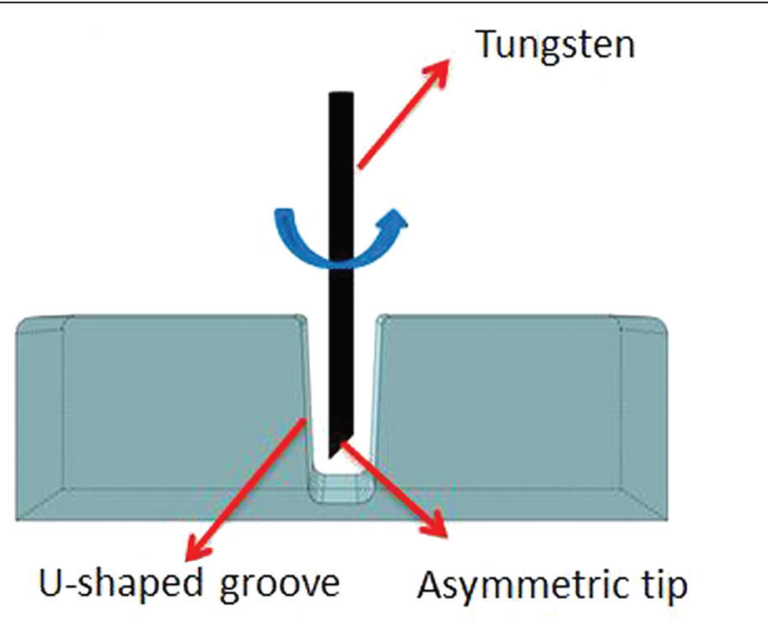

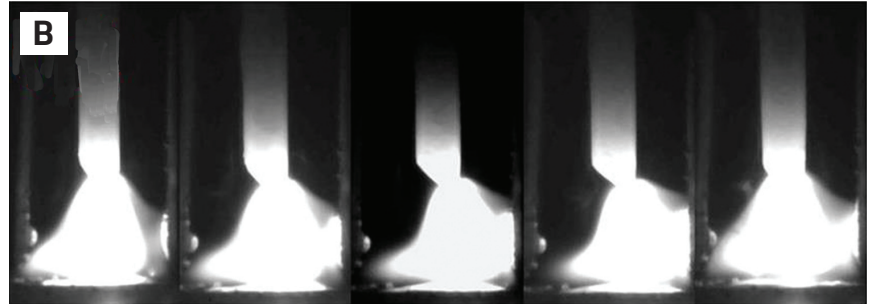

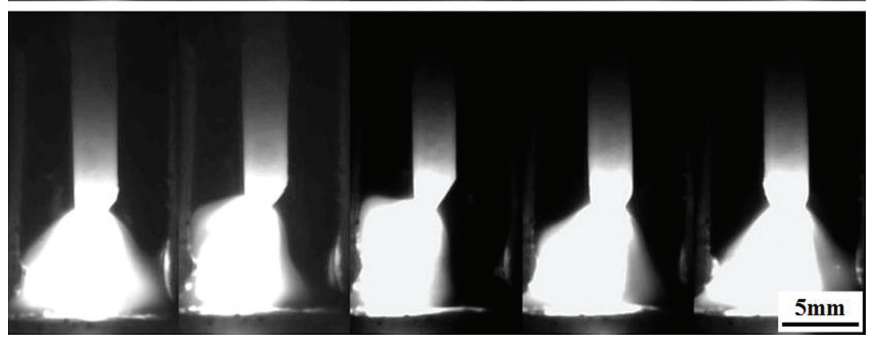

Fig. 1-Images of rotating arc behaviors using a nonaxisymmetric tungsten tip. A - Nonaxisymmetric tungsten electrode placed at the groove center; $B$ - the rotating arc generated by the rotating tungsten electrode.

welding system with two tandem wires. Sidewall fusion, productivity, and the metallurgical quality of the joints were acceptable. However, the SAW process has disadvantages, including high heat input and the presence of coarse grains caused by overheating in the weld joint. Furthermore, limited by its inherent characteristics, SAW is generally not suitable for uphill and overhead position welding.

Narrow-groove gas metal arc welding (NG-GMAW) has high welding efficiency when welding thick plates. However, single-pass-per-layer narrow-groove GMAW is prone to incomplete sidewall fusion, and centerline cracking may happen as a result of the arc climbing behavior (Refs. 11, 12). Arc characteristics have a great influence on the geometrical parameters of the weld bead such as bead width, welding penetration, sidewall penetration, and weld surface concavity (Ref. 13). Zheng et al. (Ref. 14) brought forward the method of constricting the arc with ultrafine granular flux to prevent it from climbing up (Ref. 15). However, the method required specially manufactured materials causing great limitations.

Researchers have tried to solve the insufficient sidewall fusion problem in NG-GMAW by accurate tracking, optimizing welding parameters, and arc swing or rotating. Li et al. (Ref. 16) developed an arc sensing-vision sensing system and a support vector machine (SVM) model to predict the groove state. However, the research focused on weld joint alignment, which is not helpful for energy distribution adjustment between the sidewall and below base metal. Rotating arc narrow-groove gas metal arc welding relied on the joint tracking to make enough groove sidewall penetration at both sides; higher welding current or lower welding speed resulted in better fusion between weld bead and sidewalls (Ref. 17), which caused higher heat input and deteriorated the weld joint quality. Shielding gas with the addition of helium presents a bowl weld bead profile; the depth of sidewall fusion increases with higher helium content (Ref. 18). However, the much higher cost of helium than that of argon and $\mathrm{CO}_{2}$ should be considered.

It was thought that the most effective method to solve the problem of insufficient sidewall fusion was changing the mode of arc motion. Wang et al. (Ref. 19) developed a new type of narrow-groove GMAW system, where the hollowaxis motor drives the offset nozzle and rotates the arc on the tip of the wire at high speed, so as to ensure enough penetration into the sidewalls in narrow-groove welding. However, due to the fast rotating wire, the metal transfer behavior is difficult to control and some spatters can be produced. Guo et al. (Ref. 20) exploited the asymmetric nature of rotating arc welding to minimize interlayer defects in horizontal welds. However, the obtained sidewall (below and upper) penetrations seem less than $1 \mathrm{~mm}$, which may affect the mechanical properties. Another narrow-groove welding process of single-layer single-pass type has been developed, which includes an electrode comprising a pair of intertwined wires, so there is no need for the forward end of the wire to swing within the narrow groove (Ref. 21). However, the doubled wire diameter demanded larger groove size; higher heat input was required to melt the thicker wire.

In general, for NG-GMAW, it is effective to eliminate the discontinuity of insufficient sidewall fusion by changing arc shapes, characteristics, or motion mode. Elevating the electric parameters could enlarge the total arc volume inside the narrow groove to force more arc energy be applied on the sidewalls. Changing the mode of arc motion, improving the shielding gas contents, and reducing the heat dispersion of molten pool via preheating are also candidate methods. However, it is inevitable for the NG-GMAW process to produce some splash, dust interference, and defects, which can seriously affect the welding quality.

\section{Narrow-Groove GTAW}

Narrow-groove GTAW has the advantages of high welding quality, less consumption of weld material, low heat input, high cost effectiveness, and a stable and reliable welding process. It can weld from any convenient direction and position. Wang et al. (Ref. 22) studied the up and down sidewall fusion of horizontal narrow-groove GTAW. It revealed the position of the tungsten electrode played a bigger role than the welding current in terms of its effect on the down sidewall penetration depth, and both the position of the tungsten electrode and the arc voltage had an obvious effect 




Fig. 2 - Welding system of rotating tungsten in narrowgroove GTAW.

on the up sidewall fusion behavior. Generally speaking, all the above-mentioned methods have obvious limitations in improving sidewall fusion. However, the tungsten moved around the central line; slight fluctuation may cause some defects in up or down sides, such as undercut.

It was thought that the problem of insufficient sidewall fusion in NG-GTAW could be solved via controlling the arc switching from the sidewalls. Therefore, tungsten rotation and magnetic-controlled arc oscillation have been considered as possible solutions. An approach was developed in the early 1990s by a cooperative research effort between Arc Machines, Arc Applications, and BWXT. Arc Machines Inc. designed a torch in which both the tungsten and the wire would oscillate from side to side. The alternative approach provides mechanical manipulation of the arc by rotating an angled (typically $15 \mathrm{deg}$ ) tungsten electrode. The "wiggly tungsten" model was able to overcome some of the earlier problems and provide good sidewall fusion. The results of this effort have been commercially available and successfully applied in industry for almost 20 years by Arc Machines Inc. (Ref. 23). However, the two approaches required sufficient space for tungsten oscillation or "wiggly rotation"; precise position control was demanded.

Magnetic-controlled arc oscillation is also a noteworthy alternative. Belous et al. (Ref. 24) invented a magneticcontrolled narrow-groove GTAW using an alternatively changed magnetic field to deflect welding arc toward the left or right periodically. The periodically deflected arc prevented insufficient sidewall fusion and improved the efficiency and quality of thick component welding. Wang et al. (Ref. 25) further investigated the welding process characteristics and arc pressure distribution to enhance the welding quality. In addition, Jia et al. (Ref. 26) designed an industrial automatic control system for the magnetic-controlled narrow-groove GTAW, providing a feasible way for real production. However, the magnetic-controlled narrow-groove GTAW requires complex magnetic generation and control devices; the high-intensity magnetic field will inevitably magnetize the ferromagnetic base metals, which is not acceptable in certain fields.

In view of many advantages of groove GTAW, such as good gas shielding and high welding quality, the technology

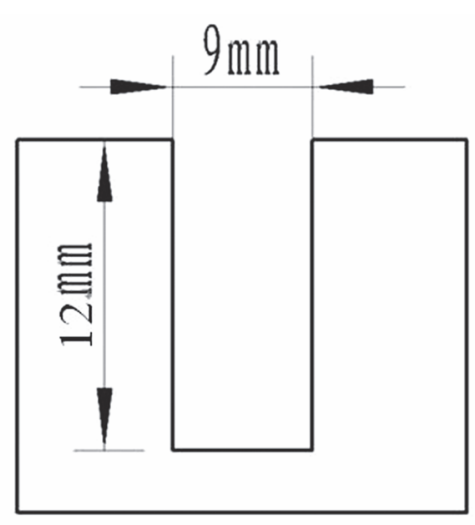

Fig. 3 - The size of groove for single-pass narrow-groove welding.

has wide application prospects in welding nonferrous metals. A novel rotating-tungsten narrow-groove GTAW (RTNG-GTAW) was proposed using a specially designed nonaxisymmetric and rotating tungsten electrode. The similarities between this paper's approach and a rotating, angled electrode or magnetic deflection are solving the problem of insufficient sidewall penetration by arc deflection. It is worth mentioning that only the nonaxisymmetric tungsten electrode and wire were extended into the groove parallel to the sidewalls. It could overcome the limitation of welding torch on groove size compared to the "wiggly tungsten" model. The paper's approach could be used to weld both ferromagnetic and nonferromagnetic materials, which make it applicable in wider ranges than the magnetic control methods.

\section{Principle and Experimental Setup}

\section{Principle}

The base metal was SHT490, a low-alloy high-tensilestrength structural steel, and the thickness was $16 \mathrm{~mm}$. The width of the narrow groove was $9 \mathrm{~mm}$. The welding wire was ER50-6 carbon steel wire, with a diameter of $1.2 \mathrm{~mm}$. As shown in Fig. 1, the rotating tungsten welding technology in narrow-groove GTAW was adopted to weld the thick plate. The motor controlled the rotation of the tungsten electrode that has been ground into a nonaxisymmetric tip. The new idea was put forward that arc is enabled to heat the base metal on both sides of the narrow groove periodically. The problem of sidewall incomplete penetration can be solved during the narrow-groove welding process. The welding equipment was composed of a new narrow-groove GTAW torch with a rotating tungsten electrode, an automatic welding tractor, a WSEM-500 welding power source, and an automatic wire feeder.

At the completion of the new type of rotating tungsten narrow-groove GTAW torch, the preliminary welding experiments were conducted. As can be seen in Fig. 1A, the nonaxisymmetric tungsten electrode was placed at the groove center. Once the arc was ignited, the welding arc always chose the shortest path from the tip to the base metal along with 


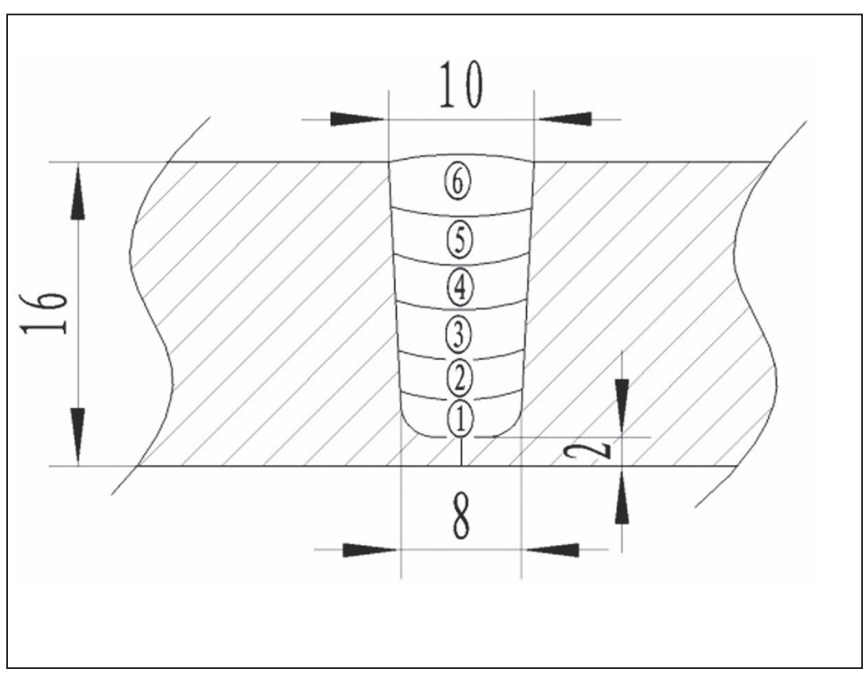

Fig. 4-U-shaped groove for narrow-groove butt joint welding.

the rotating tungsten. In this way, minimum energy was consumed to build an optimum path for current flows. Figure $1 \mathrm{~B}$ shows the rotating arc generated by the rotating tungsten electrode (150 A). The preliminary visual observation of the arc behaviors verified the possibility to control the arc heating the sidewalls and bottom metal alternatively and periodically. Sufficient sidewall penetration and highquality weld joint appearance were expected to be achieved. The preliminary experiment verified the feasibility of the proposed novel welding technology.

\section{Experimental Devices}

The system for acquiring the images and welding electrical signals was set up, as shown in Fig. 2. The effectiveness of the rotating arc on the fusion of the sidewalls was analyzed based on the images of the rotating arc caught by an industrial CCD high-speed camera. At the same time, the changes of current and voltage with the variation of the rotating arc were studied according to the waveforms collected by Hall sensors to reveal their matching relation. All these preparatory operations serve to guide further welding experiments.

It verified that it could meet the requirements of the new technology. The wire feeding stability, gas shielding effect, and rotating device were validated through the experiments. According to the process stability and welding quality, the welding torch was designed and optimized.

\section{Experimental Setup}

Single-pass and butt joint welding experiments in narrow groove were conducted. For the single-pass welding experiment, as shown in Fig. 3, the groove width was $9 \mathrm{~mm}$; the depth was $12 \mathrm{~mm}$. The diameter of the tungsten electrode was $3 \mathrm{~mm}$, with a 45-deg nonaxisymmetric tip. The welding experiments in the narrow groove were carried out by single-layer and single-pass welding in different welding currents. The penetration into the sidewalls and weld appearance were studied.

For the narrow-groove butt joint welding experiment, as

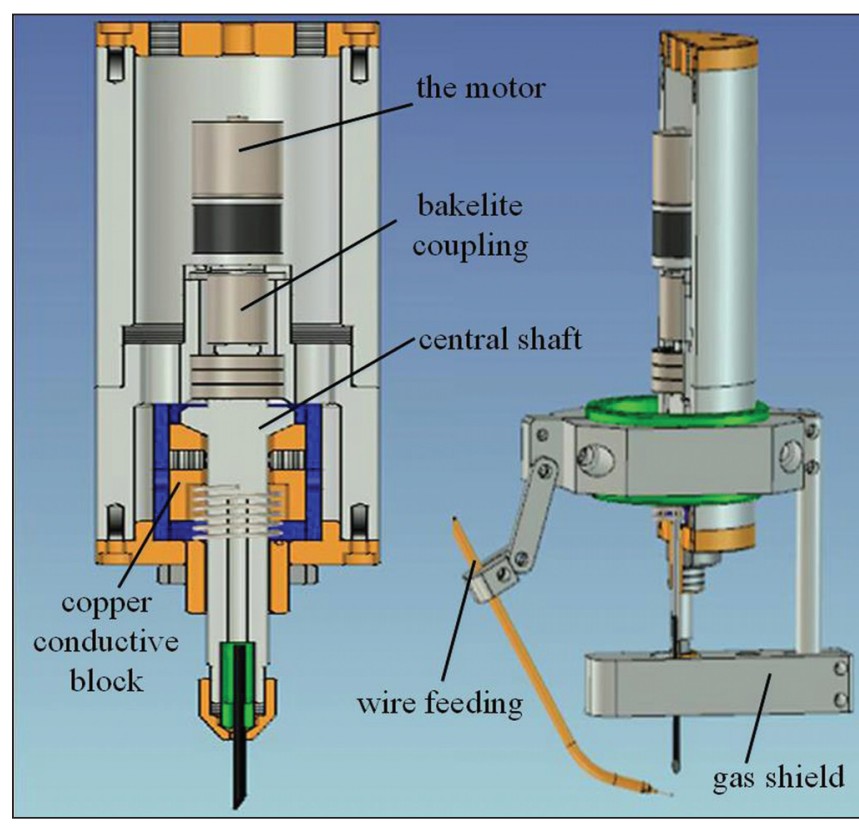

Fig. 5 - Rotating-tungsten narrow-groove welding torch design.

shown in Fig. 4, a U-shaped groove and reasonably preset welding parameters were prepared. In total, six layers of weld beam with a single pass at each layer were produced to join the 16-mm-thick steel. The penetration into the sidewalls, weld appearance, and microstructure were studied.

\section{Results}

\section{Welding Torch Design and Optimization}

According to the preliminary experiment result, the novel rotating-tungsten narrow-groove GTAW was proposed to achieve high-quality narrow-groove joints. A new rotatingtungsten narrow- groove GTAW torch was designed and manufactured. As shown in Fig. 5, the design was composed of a central rotation system, an electrical system, a wire feeding system, an air supply system, and a control box consisting of four parts. For the central rotation system, the lower part of the central shaft clamped the tungsten electrode that had been processed into a nonaxisymmetric tip; the top part was connected with the motor to control the rotation of the central shaft so as to realize the periodic change of the distance between the tungsten electrode and both sides of the narrow-groove. The central shaft and the motor were insulated with bakelite coupling to prevent the high-frequency breakdown of the motor. The electrical system was made up of a copper conductive block and a central shaft.

At the position where the copper conductive block was in contact with the central shaft, two synchro cones were processed on the contact surfaces to increase the conductive contact area, enhance the stability of conductivity, and ensure stable welding with high currents. The wire and shielding gas supply system is shown in Fig. 5. The wire feeding system consisted of an automatic argon arc welding wire feeder and a wire feeding tube, which was $6 \mathrm{~mm}$ in diameter. 


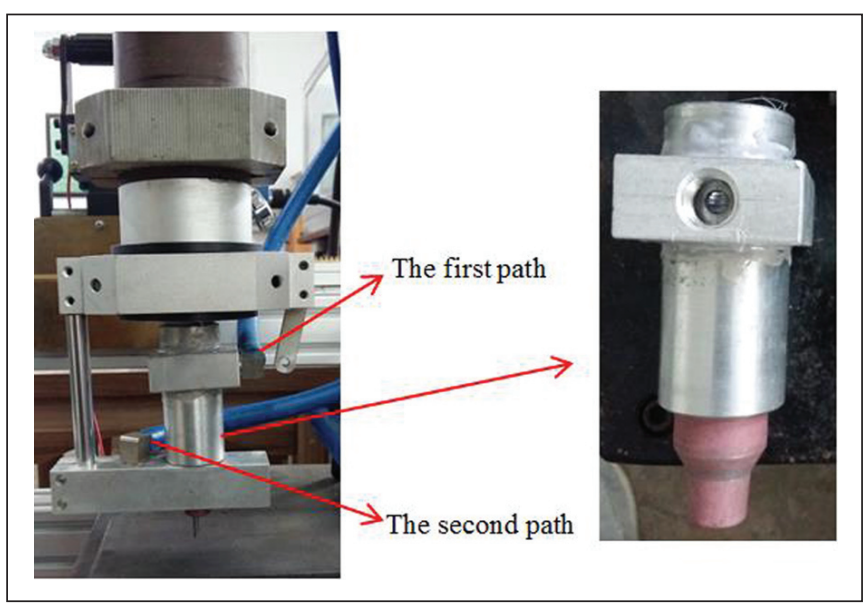

Fig. 6-Improvement scheme of gas shielding.

It was articulated with the outside of the welding torch so the angle and height of the wire feeding tubes can be adjusted. A sliding connection was arranged between the gas shield and the outside of the welding torch to allow the gas shield to slide up and down to cover the groove. The device ensured good cooperation between the wire feeding and gas protection in the multilayer welding process. The control unit controlled the rotational speed of the motor, and thus determined the rotating frequency of the arc.

Based on the newly manufactured torch, the welding experiment in narrow groove was carried out. The results showed that the welding process resulted in excessive spatters, serious oxidation, burning loss of tungsten electrode, and serious oxidation of the weld. In the experiments with different welding parameters, there was insufficient fusion at the bottom of the base metal and on both sides of the groove, and the weld appearance was convex. The authors believe that the problems can be attributed to insufficient gas shielding of the welding torch.

According to the gas shielding of a conventional GTAW torch, the scheme of dual gas protection was presented, which increased the number of central gas paths while retaining the original gas shield. Thus, the central gas paths can better protect the weld pool at the bottom of the arc to ensure stable arc burning. Meanwhile, the arc was constrained by the central gas to prevent the climbing behavior of the arc, and the shielding gas protected the weld near the weld pool from oxidation during the whole welding process. The modification of the welding torch is shown in Fig. 6.

After improving gas protection, the welding effects before and after improvement were compared as shown in Fig. 7. It was found that both welding spatter and smoke reduced in the welding process. There was no arc failure, the welding was stable, and no climbing behavior of the arc was detected, which allowed the arc to give concentrated heating to the bottom of the groove. The tungsten electrode didn't have serious burning loss during the welding process, and the weld seam was smooth and consistent after welding.

\section{Rotating Arc Behaviors}

In the process of narrow-groove welding, the signals of voltage and current were acquired in real time when the



Fig. 7-Weld appearances using the original and optimized welding torch.

Table 1 - The Forming Parameters of the Weld Section in Different Currents

\begin{tabular}{ccccc} 
Current $(\mathrm{A})$ & $\mathrm{B}(\mathrm{mm})$ & $\mathrm{H}(\mathrm{mm})$ & $\mathrm{h}(\mathrm{mm})$ & $\mathrm{Hs}(\mathrm{mm})$ \\
\hline 200 & 9.9 & 3.8 & 0.4 & 0.45 \\
250 & 10.6 & 4.1 & 0.6 & 0.8 \\
300 & 11.9 & 5.6 & 1.5 & 1.45 \\
\hline
\end{tabular}

welding current was $250 \mathrm{~A}$. The images were synchronously captured in the process. The principle was analyzed according to the collected electrical and visual signals. According to the change of electrical signals in Fig. 8, the welding current ranged from 245 to $262 \mathrm{~A}$ and the arc voltage ranged from 14 to $25 \mathrm{~V}$ with the rotation of arc. Combined with the synchronously captured arc images, it was found that the welding voltage was low when the arc rotated to the center of the narrow groove, and the arc voltage was high when the arc rotated to contact or have just moved away from the groove wall. However, when the rotating arc was in full contact with the groove wall, the arc voltage was low. The diagram of the voltage change with the periodic arc rotation is shown in Fig. 9. The periodic variation of the distance between the arc and weld pool caused the length of the arc to be alternately elongated and shortened during the process of arc rotation, which resulted in voltage change. Compared with the current, the voltage has bigger range ability. Therefore, the welding power has basically the same change tendency with the voltage. The welding power was high when the arc rotated to contact or just moved away from the groove wall. It ensures adequate heat input on the sidewalls.

\section{Single-Pass Welding}

With the new and improved rotating-tungsten narrowgroove GTAW torch and newly optimized welding technology, the interactive mechanism between the rotating arc and the sidewalls was explored in the actual welding process. Experiments were carried out to investigate whether the problem of insufficient sidewall fusion could be solved by the rotating arc in narrow-groove welding.

The experimental conditions were as follows: 4-deg angle of tungsten electrode; $0.7 \mathrm{~m} / \mathrm{min}$ wire feeding rate; 50 $\mathrm{L} / \mathrm{min}$ shielding gas; and $8.0 \mathrm{~cm} / \mathrm{min}$ welding speed. The penetration and weld appearance on sidewalls were studied by single-layer and single-pass welding. To better study the problem of insufficient sidewall fusion in the narrow- 


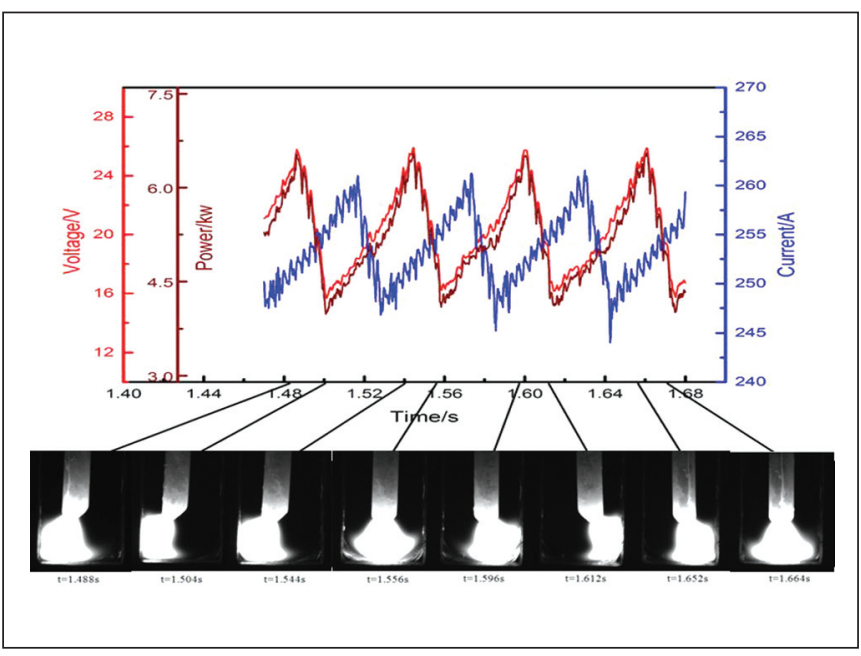

Fig. 8 - A typical rotation cycle of welding arc (power = UI).

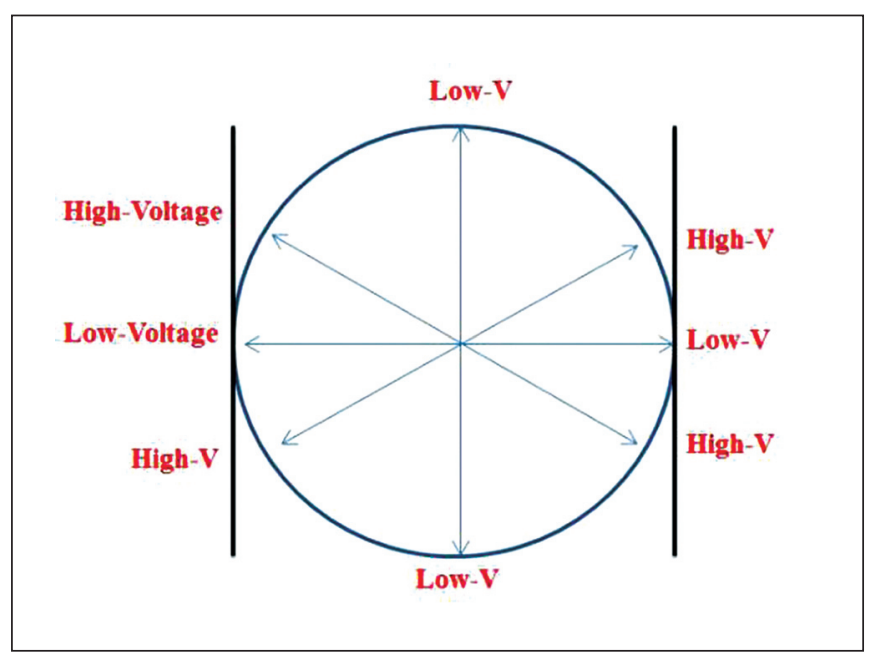

Fig. 9 - Diagram of voltage changes in a complete tungsten rotation cycle.

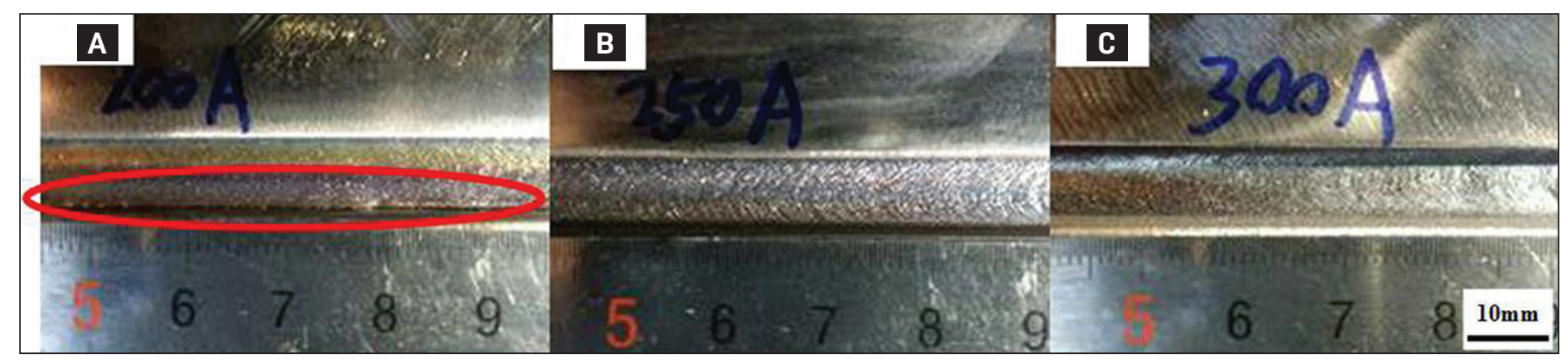

Fig. 10 - Weld appearance in different currents: A - 200 A; B - 250 A; C - 300 A.

groove welding process, the welding current was set at 200, 250 , and $300 \mathrm{~A}$, respectively. The weld appearances under different welding currents are shown in Fig. 10.

Through the observation of the weld appearance, it was found that one sidewall had insufficient fusion when the welding current was $200 \mathrm{~A}$, which caused weld defects such as undercut; however, sufficient sidewall fusion and smooth weld surface were obtained when the welding current was 250 or $300 \mathrm{~A}$. In comparison with the weld appearance before the improvement of the welding torch, the overall weld form was concave and the weld appearance presented a tidy fish-scale pattern. The reason is that during the welding process, the periodic rotation of the arc continuously stirred up the weld pool, and made the pool spread forward in a uniform and periodic manner during the cooling process. In this way, a smooth and flat weld appearance was obtained.

The above-mentioned welds were respectively processed into samples. After polishing and corroding, the parameters of the cross sections of the three weld samples were measured, including the welding pool width, weld penetration, and arc impact deg - Fig. 11. Refer to Fig. 12 for the cross section of different welds obtained from the welding processes that had three different welding currents but the same parameters.

When the welding current was $200 \mathrm{~A}$, there was almost no sidewall penetration and porosity was found at the bottom of the weld. When the welding current was 250 or 300
A, the bottom and the sidewalls of the weld had good fusion. With the elevation of welding current, the parameters of the weld cross section increased, including welding pool width, weld penetration, and arc impact deg (Table 1). Through experimental verification, the problem of insufficient sidewall fusion was solved by the new technology of rotating tungsten in narrow- groove GTAW, and a smooth and consistent appearance was obtained by properly setting the welding parameters.

\section{Narrow-Groove Thick Plates Butt Joint Welding}

A U-shaped groove (Fig. 4) was designed to solve the problems of nonpenetration at the groove foot, insufficient fusion of root angle, and deformation. Narrow-groove welding of 16-mm-thick plates was successfully carried out by designing reasonable welding parameters, as shown in Table 2 . In the welding process, the parameters of current and voltage were collected in real time to calculate weld heat input (Table 2) via the following formula:

$$
E=I U \eta / v
$$

where $E$ is the weld heat input $(\mathrm{J} / \mathrm{cm}), I$ is the welding current $(\mathrm{A}), U$ is the welding voltage $(\mathrm{V}), v$ is the welding speed $(\mathrm{cm} / \mathrm{s})$, and $\eta$ is assumed thermal efficiency (NG-GTAW $=$ 0. 85). 


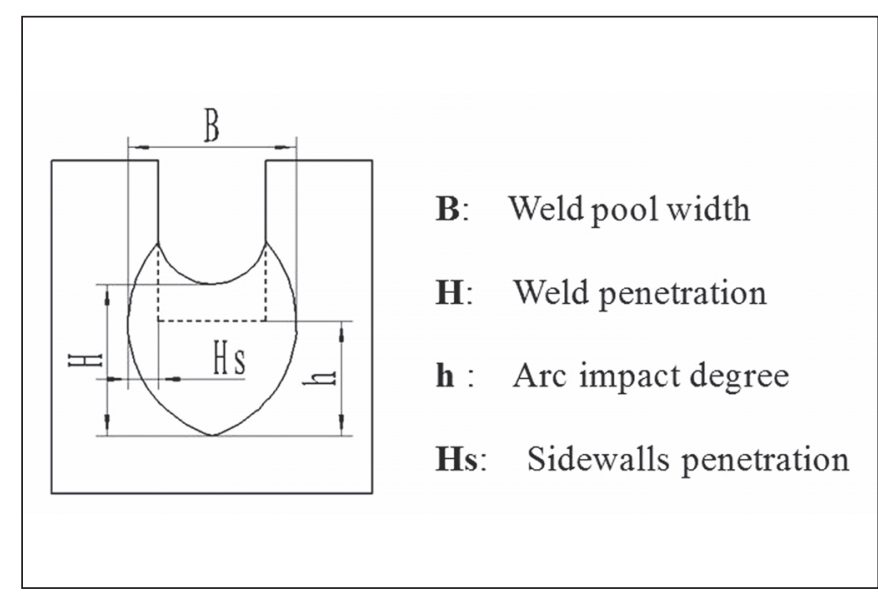

Fig. 11 - The diagram of forming parameters of a weld section.

Figure 13 shows the weld appearance and the macroscopic appearance of the welding joint of the multilayer and single-pass welding. As shown in Fig. 13A, it was found that the last pass cover weld was smooth, uniform, and free from defects such as undercut and humping. The width of the weld was obviously larger than that of the original groove. The sidewalls had good fusion and no obvious defect was detected. In addition, the fusion of interlamination was also ideal. By adopting the welding parameters in Table 2, the welding for the U-shaped groove can be completed with six layers by means of multilayer and single-pass welding.

Through analyzing the microstructure of a multilayer weld joint, it can be found that the microstructure of both weld zone and heat-affected zone (HAZ) presented special characteristics of change in the new technology of rotatingtungsten narrow-groove GTAW.

As shown in Fig. 14, since the surface weld layer was unable to receive additional thermal treatment from the succeeding layer, the microstructure of the surface layer mainly comprised thick-strip or blocky proeutectoid ferrite that was distributed along the grain boundary of the original austenite, and the crystals contained fine acicular ferrite and pearlite and sporadic granular bainite. The weld microstructure of interlayers was mainly composed of fine white ferrite, black pearlite, and a little bainite, all of which were uniformly distributed due to the additional heat treatment received from the succeeding weld.

The microstructure of HAZ mainly comprised fine ferrite and pearlite, which were uniformly distributed due to the thermal treatment. During the welding process, the hyper- thermal arc rotated periodically and stayed momentarily in the area. The arc rotation caused the area to be subject to continuous cooling, which resembled the process normalizing treatment, thus resulting in the generation of uniform and fine structure as described above. In terms of microstructure, the fusion zone mainly comprised blocky proeutectoid ferrite of different sizes that was distributed along the grain boundary of the original austenite, lath ferrite characterized by intracrystalline growth, and a little blocky pearlite and granular bainite.

The microhardness of the weld joint was tested as shown in Fig. 15. The microhardness firstly increased and then decreased in the vertical direction. The weld microstructure of the surface layer was composed of mainly thick-strip or blocky ferrite, so the microhardness was lower than the bottom of the weld. However, the highest microhardness is located at the position, which is $8 \mathrm{~mm}$ from the bottom of the weld. It is because that zone was located in the middle of the weld, which had a slow heat loss and dissipation. The lathing martensitic had consistent growth direction, and high brittleness and hardness. The weld zone had the lowest microhardness in the horizontal direction. The microhardness gradually increased from the weld zone to the base metal zone.

Through the tensile test (Fig. 16), it can be found that the tensile strength of the base metal was $540 \mathrm{MPa}$. When testing the welded sample, a fracture occurred at the base metal, which showed that the tensile strength of the weld joint was higher. It also showed that the novel welding process ensures the strength of the welded joint meets the requirements. In the bend test (Fig. 17), no crack was observed on the weld sample after bending. The excellent bending performance shows good ductility of the weld joint.

\section{Discussions}

\section{Gas Shielding}

During the rotating-tungsten narrow-groove GTAW, insufficient gas shielding seriously affected the stability of the welding process. Therefore, it is critical to provide good shielding for the welding arc, weld pool, and surrounding metal. Optimized gas shielding had mainly four functions, including preventing the oxidation of high-temperature weld pool and surrounding metal, providing sufficient ionization gas, regulating the arc behaviors in the narrow groove, and cooling the tungsten electrode effectively.

First, the thick plate with a narrow groove caused a long travel distance for the shielding gas from the nozzle to the

Table 2 - The Welding Process Parameters of Multilayer and Single-Pass Welding

\begin{tabular}{cccccc}
$\begin{array}{c}\text { Weld Pass } \\
\text { Number }\end{array}$ & $\begin{array}{c}\text { Welding Current } \\
\text { (A) }\end{array}$ & $\begin{array}{c}\text { Arc Voltage } \\
\text { (V) }\end{array}$ & $\begin{array}{c}\text { Wire-Feed Rate } \\
(\mathrm{mm} / \mathrm{min})\end{array}$ & $\begin{array}{c}\text { Welding Speed } \\
(\mathrm{cm} / \mathrm{min})\end{array}$ & $\begin{array}{c}\text { Heat Input } \\
(\mathrm{kJ} / \mathrm{cm})\end{array}$ \\
\hline 1 & 220 & 18 & 600 & 10 & 20.20 \\
2 & 250 & 18 & 600 & 700 & 10 \\
3 & 260 & 18 & 600 & 8 & 23.95 \\
4 & 260 & 17 & 600 & 8 & 28.65 \\
5 & 260 & 16 & 600 & 8 & 26.52 \\
6 & 280 & 16 & & 8.56 \\
\hline
\end{tabular}





Fig. 12 - Weld appearance of the cross section of single-layer and single-pass welding: $A-200 A ; B-250 A ; C-300 A$.

groove bottom. High-rate gas flow was required to guarantee that sufficient argon was delivered to the welding area. The air was then discharged and kept off by the continuously fed argon. Thus, the high-temperature liquid and solid metal could be well protected.

Second, except for the protection for high-temperature metals, stable arc ignition and burning required the same amount of argon as ionization gas. Experiments by the authors showed that insufficient argon atmosphere caused splash, unstable welding arc, and some porosity defects. The authors deduced the amount of argon was consumed for arc plasma ionization. Therefore, it was possible that some oxygen and hydrogen invaded the area causing unstable arc burning. The disturbance could be eliminated by the proposed enhance gas shielding from both central and auxiliary gas paths.

Third, the arc climbing behavior is critical for narrowgroove welding methods. As for the rotating-tungsten narrowgroove GTAW, the distance between the tungsten column and sidewalls is almost the same as that between tungsten tip and sidewalls. According to the principle of minimum energy, the welding arc does not have to burn between the tip and base metal. Arc climbing behavior was found when only using the original gas shielding in Fig. 5. According to previous research results, if the cold shielding gas was blown along the sidewalls, the problem could be eliminated. With the optimized gas shielding device, the generated laminar gas flow along the sidewalls successfully gathered the welding arc together.

The authors deduced the cold gas flow could significantly increase the temperature difference between the tungsten tip and the tungsten column. For nearly the same argon shielding gas, the lower temperature increased the ionization energy of the gas between tungsten column and sidewalls. Therefore, in comparison with the above space, the atmosphere around the welding area owned lower ionization energy property; the welding arc was prone to keep burning stably at the groove bottom without climbing up. Thus, the arc was forced to intensively heat the bottom sidewalls; sufficient penetration on sidewalls could be obtained. At last, the adequate argon gas flow provided effective cooling for the tungsten electrode. In narrow-groove GTAW, the tungsten was heated to a high temperature by high welding current. Cold and inert gas flow provided important protection both during and shortly after the welding process.

\section{Tungsten Tip Erosion}

Tungsten tip erosion is a problem that must be consid- ered in the GTAW process. Compared to conventional GTAW and the previously mentioned NG-GTAW, the electrode erosion for the presented welding method has almost the same factors. Studies by Suga et al. (Ref. 27) showed that electrode erosion is greater when an alternating current is used than when an electrode-negative direct current is used. Tungsten electrode erosion increases with the welding current and lapse of time. In the present research, an electrodenegative direct current was used under limited welding current less than $280 \mathrm{~A}$. In addition, it is necessary to control the interlayer temperature. In this way, the tungsten tip has enough time for cooling during this period; fine microstructure of the weld joint could be obtained.

The effect of electrode erosion is considered to be strongly dependent on the temperature distribution of the electrode tip during welding. According to the research (Ref. 27), the electrode tip during arc striking has a temperature as high as around $3000 \mathrm{~K}$, being readily susceptible to the effect of the arc. The high-temperature region increases simultaneously with a rise in the electrode tip temperature with an increasing current. As shown in Fig. 6, the scheme of dual gas protection contributed to reducing tungsten erosion. The central gas paths and the gas shield ensured the more adequate argon gas flow in the groove, which provided effective cooling for the tungsten electrode.

Also, according to previous research (Ref. 23), tungsten quality, tungsten type, and tip geometry are all important for GTAW. In a helium-rich shielding gas environment, Babcock and Wilcox found that lanthanated tungsten electrodes were preferred for longevity. Yang et al. found two better ways, including ensuring the purity grade and flow rate of shielding inert gas and using a tungsten electrode activated with nanosized thoria can decrease the erosion rate of an electrode (Ref. 28). Li et al. verified that while the mass loss of La-W1 was lowest and the tip size of La-W1 was relatively stable when comparing several new rare-earth tungsten electrodes (E3, ErW, La-W1, and La-W2) (Ref. 29). The previous research (Ref. 24) proposed that a larger diameter electrode, such as $5 / 32$ in. (about $4 \mathrm{~mm}$ ) with a blunt tip, was required for increased penetration and erosion resistance during hot wire NG-GTAW. In addition, fine grain electrodes with a homogenous distribution of oxides are required for erosion resistance and arc length stability (Ref. 24).

Since this paper only conducted preliminary research on the novel RT-NG-GTAW, a common cerium tungsten electrode $(\mathrm{W}-\mathrm{Ce})$ with a $3.2 \mathrm{~mm}$ diameter was employed. The erosion resistance mostly depended on the gas shielding and 


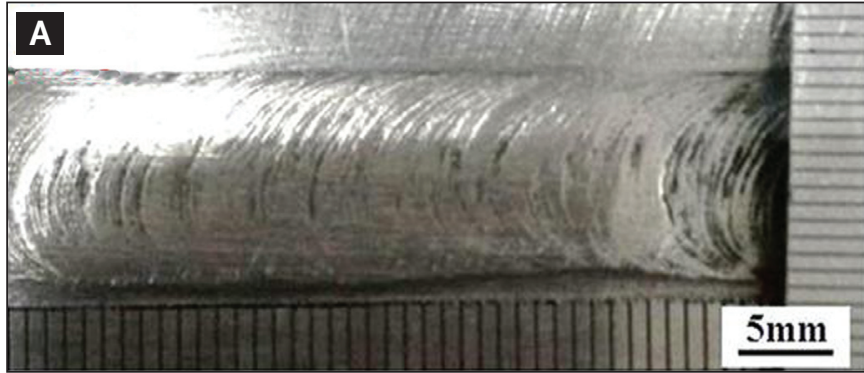

Fig. 13 - Surface layer and cross-section appearance of butt-joint welding: $A-$ Weld appearance of surface layer; $B$ - weld appearance of cross section.

cooling effect, welding current, and welding duration. Although an acceptable erosion of a tungsten electrode was achieved, further research is expected in the near future to fulfill the industrial demand.

\section{Heating on the Sidewalls}

Periodically changing electrical signals guaranteed stable and reliable heating on the sidewall metals. Compared with the current, the voltage has a bigger range of variation. As shown in Fig. 8, the welding current varied in the amplitude of $17 \mathrm{~A}$ at maximum, about $6.8 \%$ of the preset value of $250 \mathrm{~A}$, while the arc voltage varied within a range up to $11 \mathrm{~A}$, about $78 \%$ of the lowest value of $14 \mathrm{~V}$ and $44 \%$ of the highest value of $25 \mathrm{~V}$. Accordingly, the power input to the welding process varied with a significant amplitude. As shown in Fig. 8, the lowest power input value was about 3.85 and $6.9 \mathrm{~kW}$, respectively. That produced nearly a sawtooth waveform to periodically heat the sidewall metal. Please note that because the welding current changed slightly, the welding power input has almost the same tendency as the voltage.

According to the Principle of Minimum Voltage, the arc was forced to melt through the shortest path. It was thought that the fluctuated heating power is mainly due to the periodically changing minimum distance from the tungsten tip to the base metal (including sidewalls and below metal). Because the tungsten tip height (about 3.5 $\mathrm{mm}$ ) was set to be higher than the distance between tungsten, cylinder, and sidewall (about $2.9 \mathrm{~mm}$ ), meanwhile be smaller than half the value of groove dimension (about 4.5 $\mathrm{mm}$ ), this guaranteed the demanded arc switching phenomenon from sidewalls to below metal periodically. The welding power input was high when the rotating arc had just contacted with or was leaving the sidewall. At these moments, the distances from the tungsten tip to base metal were largest according to its space positions. The lengthened welding arc produced higher arc voltage. The heat input on the sidewall determining the penetration could be much higher than the low-voltage moments. This characteristic helped to increase heating time and heat input on the sidewalls, ensuring sufficient penetration. Power changes help to keep sufficient heat input to compensate the distance enlargement between the arc and the sidewall.

However, considering the heat distribution on the sidewall and the bottom weld pool, the real heat input on the sidewalls was not as high as the total power input. Part of

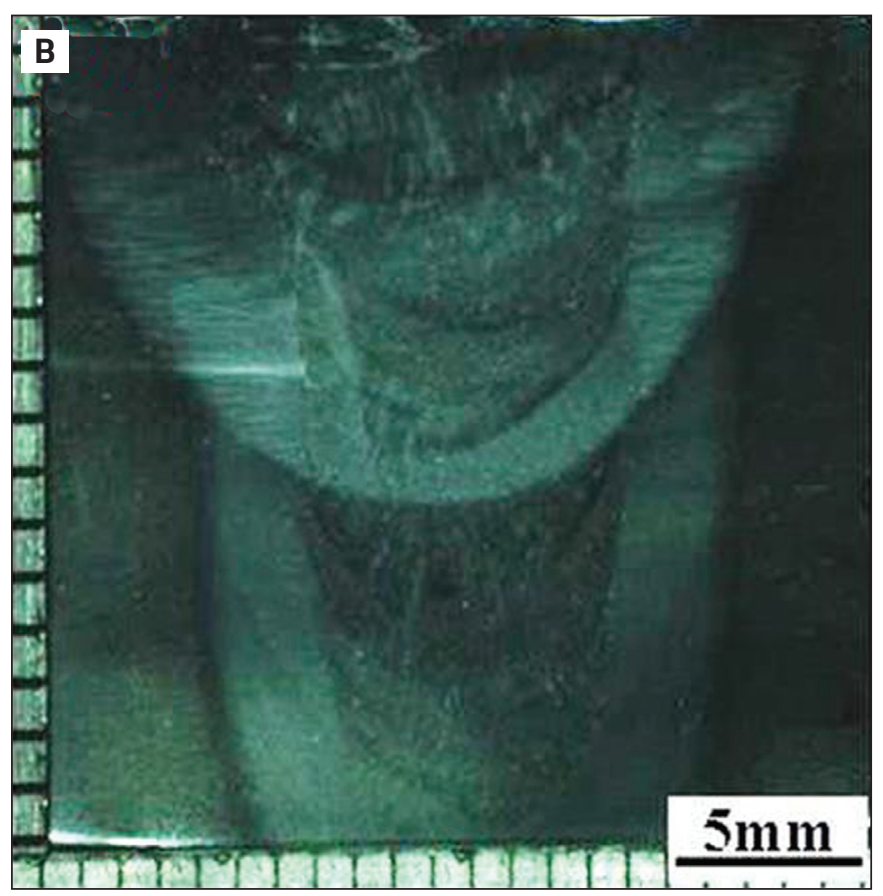

the welding arc burned between the tungsten tip and the bottom weld pool. Therefore, the sawtooth waveform heat input could guarantee sufficient sidewall penetration and meanwhile ensured the bottom weld pool was heated in a lower level to decrease the total heat input.

\section{Pros and Cons of RT-NG-GTAW}

The rotating arc produced by a rotating nonaxisymmetric tungsten electrode could keep burning periodically on the sidewalls and bottom weld pool. However, according to the low-current welding experiments, the insufficient heat input could not provide enough impact on the molten or solid metal. In this case, incomplete penetration on the sidewalls happened; uneven cross-section welds might be produced. Once the welding current reached a certain level (>250 A), this problem could be solved. It was deduced from the arc behaviors and electrical signals, low-level welding current could not produce enough arc plasma inside the groove; the plasma arc column was not stiff enough, which caused the oppressed gas flow on the bottom weld pool.

The following experiments showed that the rotating arc cooperating with appropriate welding current could adequately solve the problem of insufficient sidewalls fusion in narrow-groove welding. The higher welding current ensured adequate stiffness of the plasma arc. Stable arc burning between sidewalls and tungsten tip was realized. Furthermore, the periodic rotating arc continuously stirred the weld pool making the liquid metal spread forward in a uniform and periodic manner during the cooling process. This ensured the fine microstructures and high-performance properties of the weld joint.

Compared to aforementioned similar NG-GTAW methods, including rotating arc using 15 deg "wiggly tungsten" and deflected arc produced by a high-intensity alternating magnetic field, the newly proposed method owns some merits and demerits. 

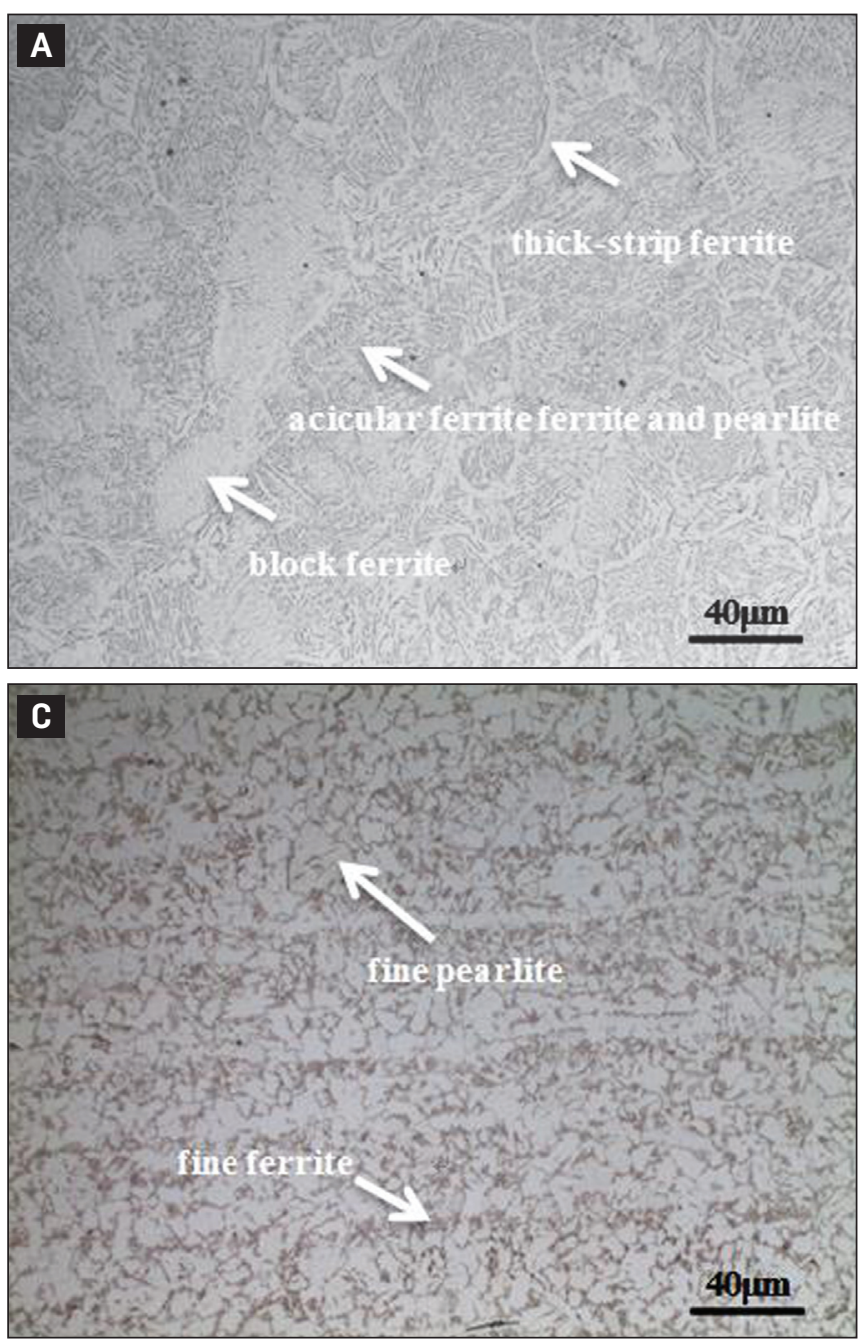
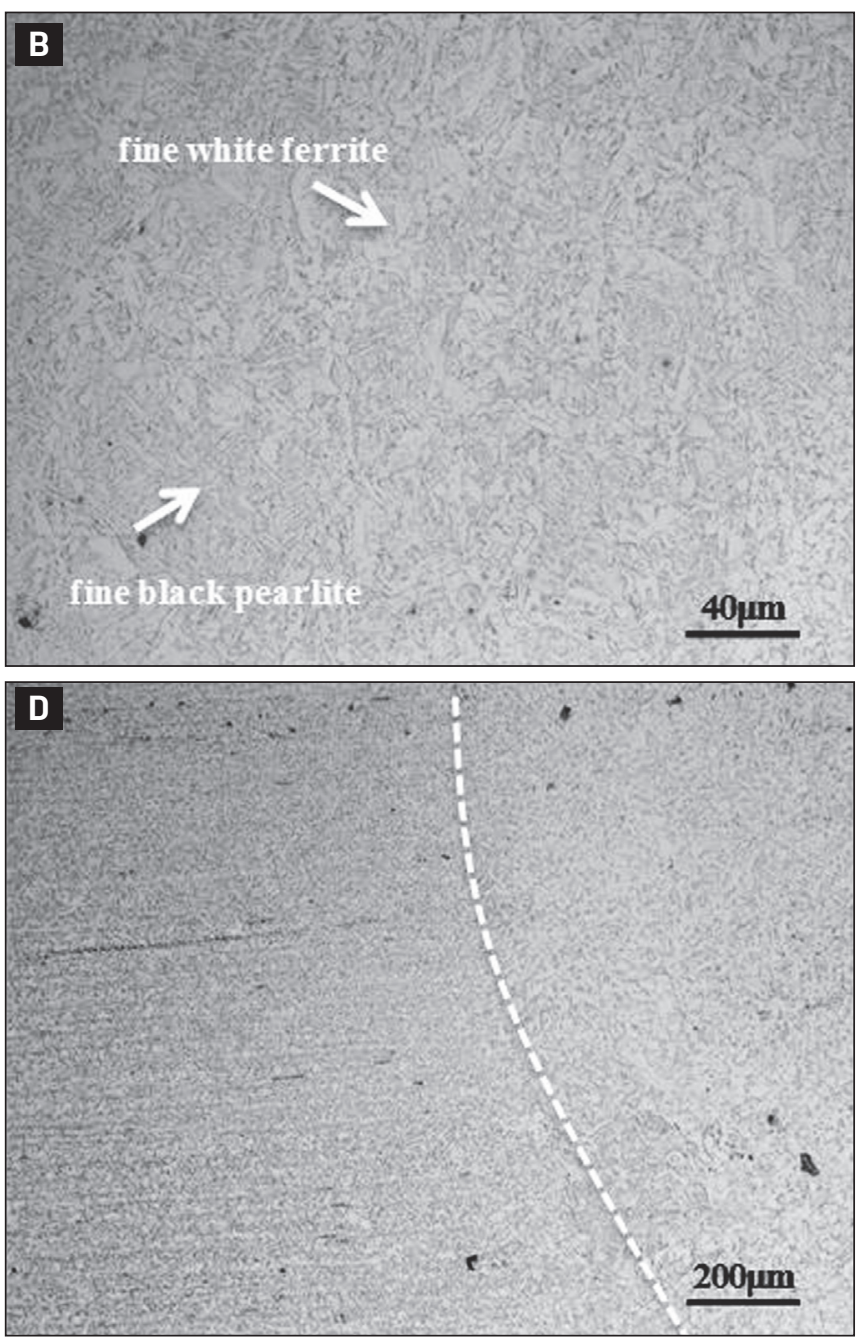

Fig. 14 - The microstructure of a multilayer welding joint: A - The microstructure of surface layer; B - the interlayer microstructure; $C$ - the microstructure of HAZ; D - the microstructure of fusion zone.

The pros of this novel technology could be summarized as follows:

First, the simple tungsten rotation realized the welding arc motion control of shifting periodically from sidewalls to bottom weld pool. No magnetic field is required as in the magnetic controlled NG-GTAW; thus both ferromagnetic and nonferromagnetic materials could be welded using NGGTAW. The tungsten does not have to be angled like the "wiggly tungsten"; thus the groove dimension was only limited by the tungsten diameter rather than determined both by tungsten diameter and its angle of inclination.

Second, the ultra-narrow-groove (less than $6 \mathrm{~mm}$ ) GTAW is expected to be realized in the near future based on the newly proposed technology. No permeability magnetic material is required to be extended close to the welding area to produce a high-intensity magnetic field, which generally demands sufficient groove dimensions. No inclination of tungsten is required to produce varying distances between tungsten tip and sidewalls, which inevitably demands sufficient space for wiggly tungsten rotation. The ultra-narrow groove is determined only by the required electrode diameter. That is to say, if low welding current is used like $100 \mathrm{~A}$, tungsten diameter could be less than $2.0 \mathrm{~mm}$; the root opening di- mension could be slightly larger than the tungsten diameter, which makes it easy to realize a 5-mm groove GTAW.

Third, the newly proposed technology is more low cost and robust than the two aforementioned methods. No magnetic generation device is required; a common low-power motor could well support the tungsten rotation. For the current technology, it is not necessary to precisely position the tungsten tip using a gauge like the method using a rotating, angled electrode. According to the experimental experience from the authors, an ocular estimate for electrode centering between the sidewalls is adequate to obtain acceptable weld joints. Note the deducing needs to be quantitatively verified using intentionally designed slight deviations of the tungsten electrode.

For the cons of this new technology, it could be concluded as follows:

First, the arc shifting from bottom metal to sidewalls is not as strong as the magnetic-controlled method. The deviation of the welding arc is gentler, which is the reason why low welding current could not produce significant sidewall penetration.

Second, the arc climbing behavior is prone to happen compared to both the rotation angled tungsten GTAW and 
A



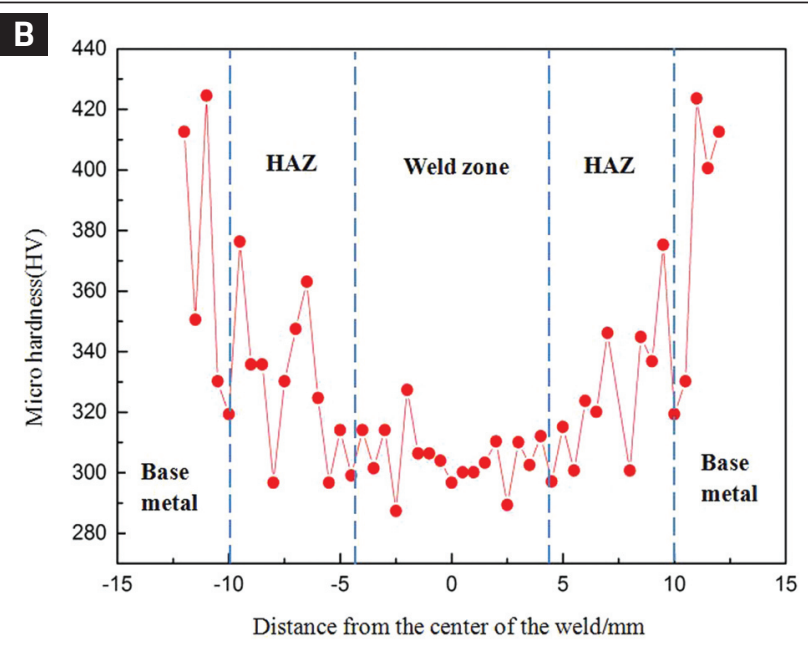

Fig. 15 - The microhardness of a multilayer weld joint: $A$ - The microhardness in the vertical direction; $B$ - the microhardness in the horizontal direction.
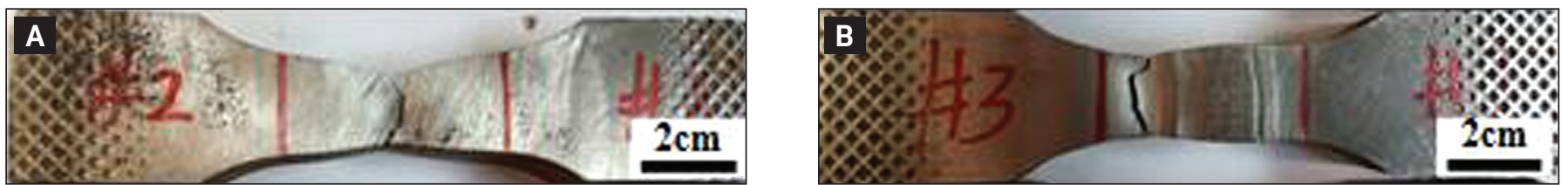

Fig. 16 - The tensile test samples: A - The base metal; B - the welding joint.



Fig. 17 - The ductility properties using a bend test.

magnetic-controlled NG-GTAW, because the distance from the cylinder wall to sidewalls is nearly constant from bottom to top. Sufficient shielding gas along the sidewalls is required to avoid this.

The pros and cons of this novel technology show it has both the research and commercial potential to be widely used in welding thick plate of various materials, including mild steel, stainless steel, aluminum, Inconel ${ }^{\circledR}$ steel, and 9\% $\mathrm{Ni}$ steel. The consumable material could be significantly reduced with better weld joint quality. Human working hours, residual stress, and distortion are all expected to be reduced.

\section{Interlayer Interactions}

Multilayer welding is a comprehensive function, made up of many single-layer thermal cycles. From one side, during the experiments, the authors welded the next layer after the previous one was cooled below $50^{\circ} \mathrm{C}$. This helped to prevent serious heat accumulation and further caused coarse microstructures. When welding the subsequent weld joint, the rotating arc and newly molten liquid metal both heated the previously solidified metal. Recrystallization happened, which helped the temporarily generated coarse microstructures turn into fine microstructures. At the same time, some minor defects on the surface and (if they existed) in the weld joint could be removed. Under the stirring effect by the rotating arc, part of the previous layer and newly molten metal were mixed together. This helped to ensure sufficient element exchanges and to even metallurgy distribution between the adjacent layers.

From the other side, as shown in Fig. 13B, although the interlayer temperature was controlled at low temperature, the weld joint and HAZ dimensions can be observed larger, especially the fourth, fifth, and sixth layers. This was due to the increased heat input, according to Table 2. The heat input was increased by elevating welding current and lowering welding speed to produce a stronger welding arc compensating the enlarging groove dimension. It was necessary to provide sufficient heating on both sidewalls and adequate liquid metal to build a reliable weld joint and to ensure enough sidewall penetration. According to this preliminary investigation, the authors believe that more precise predeformation and heat input control could help to make the weld joints uniform in the future.

\section{Microstructure Evolution and Mechanical Properties}

The microstructure of both the weld zone and HAZ presented different characteristics using the rotating-tungsten narrow-groove GTAW. First, the surface layer had a coarser microstructure and larger grain sizes compared to bottom 
and interlayers, as shown in Fig. 14A. It is thought that the main reason was the continuous heating style on the flat weld pool rather than a deep and narrow groove, which caused a smaller heated zone area and deteriorated heat dissipation condition. When welding in the narrow groove, the rotating arc heated the sidewalls and bottom weld pool alternatively; the heating area was U-shape and three-dimensional; the heated area was larger than a flat and circle area; and the welding current density on the heating surfaces were more uniform. Furthermore, the surrounding sidewalls and the bottom previously solidified metal provided multidirectional heat dissipation channels via conduction. Heat accumulation could be effectively avoided.

Second, Fig. 15A shows that the weld joint between the third and fourth layers owned the highest hardness compared to all the layers. It was deduced the heat treatment on the third layer when welding the fourth layer provided thorough recrystallization for solidified metal. By comparison, the first and second layers both went through low heat input and incomplete recrystallization by the succeeding welding. The rotating arc produced by low welding current was not strong enough to completely melt the previously solidified metal. While the fourth, fifth, and sixth layers were welded using high heat input; the grain was coarse causing lower hardness values.

Third, the HAZ shows fine pearlite and ferrite microstructures, according to Fig. $14 \mathrm{C}$. The rotating arc heats the sidewalls and bottom weld pool alternatively and periodically. Rapid switch of the heating positions between different welding areas produced a kind of "pulsed" heating. In this case, both sidewalls were heated shortly; then the arc switched to the next area; cooling time of the just heated zone began; after almost a complete circle, the rotating arc reached the area again; and a new heating circle began. The "pulsed" heating and cooling on the sidewall metal avoided heat accumulation. No overheating happened, and fine microstructures were ensured.

Overall, during the rotating-tungsten GTAW process, the rotating arc produced discontinuous heating on the surrounding metals, including both sidewalls and bottom weld pool. Interactions between adjacent layers and arc rotation behaviors applied on the weld zone and HAZ. The special thermal circles were similar to normalizing treatment, which resulted in uniform and fine microstructures as described above. The weld joint obtained excellent mechanical properties, including high tensile strength and good ductility. The complete and reliable sidewall penetration was achieved by the novel rotatingtungsten narrow-groove GTAW.

\section{Conclusion}

1) The novel technology of rotating-tungsten narrowgroove GTAW achieved good weld appearance and sufficient sidewall penetration when welding thick plates in a narrow groove. This technology is promising in thick-plate welding for several advantages. Sufficient sidewall penetration could be obtained without any magnetic control or complex tungsten clamping mechanism. Ultra-narrow-groove GTAW is expected to be realized in the future. Since the wire diameter is generally smaller than $2.0 \mathrm{~mm}$, the minimal groove for this novel technology is only limited by the tungsten diameter.
2) The new welding torch can control the rotation of the arc in the narrow groove, and the advantages include perfect gas shielding, steady wire feeding, sufficient sidewall fusion, concave and fish-scale weld joint, as well as absence of oxidation. Stable rotating arc can periodically heat the sidewall and weld pool at the bottom. The current and arc voltage changed periodically because of the distance between the tungsten tip and the liquid metal surface. The weld power ensured adequate heat input on the sidewall.

3) The periodic arc rotation had a stirring effect on the weld pool, and the ideal heating effect on sidewalls guaranteed good sidewall fusion, smooth weld appearance, and absence of coarse grains caused by overheating in the weld joint. The interlayer microstructure of the weld mainly comprised fine white ferrite, black pearlite, and a little bainite, all of which were uniformly distributed. The microstructure of surface layer mainly comprises thick-strip or blocky proeutectoid ferrite.

4) The microstructure of HAZ mainly comprised uniformly distributed fine ferrite and pearlite. The microstructure of fusion zone was mainly composed of blocky proeutectoid ferrite. Under general conditions, the microstructure has a small grain size and normal hardness distribution.

5) Mechanical tests indicated that the maximum strength reached $660 \mathrm{MPa}$. Fracture occurred at the position of the base metal. A bend test verified that the weld joint had good ductility. The technology of novel rotating-tungsten groove GTAW perfectly realized the welding of 16 -mm-thick plates by the way of multilayer and single-pass welding.

\section{References}

1. Cook, G. E., and Levick, P. C. 1985. Narrow gap welding with the hot wire GTA process. Welding Journal (64)8: 27-s to 31-s.

2. Sawada, S., and Hori, K. 1979. Application of narrowgap process for the fabrication of heavy wall pressure vessels. American Welding Society $60^{\text {th }}$ Annual Meeting, Detroit, Mich. April 2-6.

3. Feng, J. C., et al. 2017. An evaluation of multipass narrow gap laser welding as a candidate process for the manufacture of nuclear pressure vessels. International Journal of Pressure Vessels and Piping 157: 43-50. DOI: 10.1016/ j.ijpvp.2017.08.004

4. Feng, J., Guo, W., Francis, J., Irvine, N., and Li, L. 2016. Narrow gap laser welding for potential nuclear pressure vessel manufacture. Journal of Laser Applications 28(2): 022421. DOI: $10.2351 / 1.4943905$

5. Buddu, R. K., Chauhan, N. L., and Raole, P. M. 2014. Investigations of microstructure and mechanical properties of 60-mm-thick type 316L stainless steel welded plates by multipass tungsten inert gas welding and electron beam welding for fusion reactor applications. Fusion Science Technology 65(2): 248-254. DOI: 10.13182/FST13-662

6. Elmesalamy, A. S., Li, L., Francis, J. A., and Sezer, H. K. 2013. Understanding the process parameter interactions in multiple-pass ultra-narrow-gap laser welding of thicksection stainless steels. International Journal of Advanced Manufacturing Technology 68(1-4): 1-17. DOI: 10.1007/s00170-013-4739-x 
7. Elmesalamy, A., Francis, J. A., and Li, L. 2014. A comparison of residual stresses in multipass narrow gap laser welds and gas-tungsten arc welds in AISI 316L stainless steel. Journal of Advanced Manufacturing Technology 113: 49-59. DOI: 10.1016/j.ijpvp.2013.11.002

8. Nilsen, M., Sikström, F., Christiansson, A. K., and Ancona, A. 2016. Vision and spectroscopic sensing for joint tracing in narrow gap laser butt welding. Optics \& Laser Technology Journal (96): 107-116. DOI: 10.1016/j.optlastec. 2017.05.011

9. Hantsch, H., Million, K., and Zimmerman, H. 1982. Submerged arc narrow-gap welding of thick-walled components. Welding Journal 61(7): 27-s to 34-s.

10. Manzoli, T., and Caccia, E. 1989. Narrow gap welding of heavy gauge steel nuclear components. Welding International 3(5): 417-423. DOI: 10.1080/09507118909447675

11. Gu, Y., He, G., Shi, Y., He, W., and Zhu, M. 2016. Detection and analysis of arc shape and droplet transfer behavior of narrow gap GMAW. Journal of Shanghai Jiao Tong University 50(10): 1526-9, 1534. DOI: 10.16183/j.cnki.jsjtu. 2016.10.003

12. Laing, B., Heid, R., Pollack, A., and Taylor, D. H. 1985. Narrow gap welding of 2' HY-100 plate using closed loop, adaptive-feedback, through-the-arc tracking technology. Welding for Challenging Environments - Proceedings of the International Conference on Welding for Challenging Environments. Toronto, Ontario, Canada, October 15-17. Pages: 117-129. DOI: 10.1016/B978-0-08-031866-0.50016-0

13. Zhu, C., Tang, X., He, Y., Lu, F., and Cui, H. 2016. Characteristics and formation mechanism of sidewall pores in NG-GMAW of 5083 Al-alloy. Journal of Materials Processing Technology (238): 274-283. DOI: 10.1016/j.jmatprotec. 2016.07.032

14. Zheng, S. 2011. Constricted arc by ultra-fine granular flux applied to ultra-narrow gap welding. Journal of Mechanical Engineering 47(8): 83-87. DOI: 10.3901/JME.2011.08. 083

15. Zheng, S. 2009. Constricted arc by flux strips applied to ultra-narrow gap welding. Chinese Journal of Mechanical Engineering 45(2): 219-223.

16. Li, W., Gao, K., Wu, J., Hu, T., and Wang, J. 2014. SVM-based information fusion for weld deviation extraction and weld groove state identification in rotating arc narrow gap MAG welding. International Journal of Advanced Manufacturing Technology 74(9-12): 1355-1364. DOI: 10.1007/ s00170-014-6079-x

17. He, Y., Tang, X., Zhu, C., Lu, F., and Cui, H. 2017. Study on insufficient fusion of NG-GMAW for $5083 \mathrm{Al}$ alloy. International Journal of Advanced Manufacturing Technology
92(9-12): 4303-4313. DOI: 10.1007/s00170-017-0485-9.

18. Cai, X., Fan, C., Lin, S., Ji, X., Yang, C., and Guo, W. 2017. Effects of shielding gas composition on arc properties and wire melting characteristics in narrow gap MAG welding. Journal of Materials Processing Technology 244: 225-230. DOI: 10.1016/j.jmatprotec.2017.01.036

19. Wang, J., Guo, H., and Yang, F. 2005. New type of high speed rotating arc GMAW narrow gap welding. Transactions of the China Welding Institution 26(10): 65-67.

20. Guo, N., Lin, S. B., Gao, C., Fan, C. L., and Yang, C. L. 2009. Study on elimination of interlayer defects in horizontal joints made by rotating arc narrow gap welding. Science and Technology of Welding and Joining 14(6): 584-588. DOI: 10.1179/136217109X456942

21. Kimura, S., Ichihara, I., and Nagai, Y. 1979. Narrowgap, gas metal arc welding process in flat position. Welding Journal 59(7): 44-s to 52-s.

22. Wang, M., Lü, X., Liang, X., and He, S. 2016. Investigation on sidewall fusion behavior of horizontal narrow gap TIG. Transactions of the China Welding Institution 37(6): 118-123.

23. Henon, B. K. 2010. Hot wire narrow groove welding and cladding with nickel-based alloys, pp. 20-23. www.nuclear-exchange.com/pdf/tp_archmachines.pdf.

24. Belous, V. Y., and Akhonin, S. V. 2007. Influence of controlling magnetic field parameters on weld formation in narrow-gap argon-arc welding of titanium alloys. The Paton Welding Journal (4): 2-5.

25. Wang, J., Sun, Q., Feng, J., Wang, S., and Zhao, H. 2016. Characteristics of welding and arc pressure in TIG narrow gap welding using novel magnetic arc oscillation. International Journal of Advanced Manufacturing Technology 90: 413-420. DOI: 10.1007/s00170-016-9407-5

26. Jia, C., Du, Y., Wu, C., and Yuan, X. 2017. Design of an automatic control system for magnetic controlled narrow-gap TIG arc welding of thick plates. Journal of South China University of Technology 45(9): 40-46. DOI: 10.3969/ j.issn.1000-565X.2017.09.006

27. Suga, Y., Ogawa, K., and Matsumoto, H. 1992. Erosion characteristics and temperature distribution of tungsten electrodes in TIG welding. Welding International 6(5): 362-367. DOI: 10.1080/09507119209548203

28. Yang, Z., Wang, W., Ogawa,Y., and Ding, B. 2005. Effect of oxygen contamination on erosion of tungsten electrode in GTA welding. Rare Metal Materials \& Engineering (34)11: 1806-1809.

29. Li, P., Yang, J., and Li, Y. 2017. Welding performance of several new rare earth tungsten electrodes. Materials Science Forum 898: 1117-1122. 